\title{
The prevalence of human retroviral infections in female patients attending a central London sexually transmitted disease clinic: 1985-1990
}

\author{
Clive Loveday, Danielle Mercey
}

\begin{abstract}
Objectives-To determine the prevalence of infection with HIV-1, HIV2, HTLV-1 and HTLV-2 in female attenders at a central London sexually transmitted disease clinic in an 8 week period in 1989-1990, and compare it with similar samples studied between 1985 and 1987. Design-Anonymous testing of serum samples from consecutive female patients having routine serological investigation for syphilis. Testing was for clinically important retroviruses, Hepatitis B core antibodies (anti-HBc), and p24 and reverse transcriptase (RT) antigens. Age (in 5 year bands), nationality (in broad geographical zones), diagnosis on the day of presentation, and history of intravenous drug usage were recorded for each patient. Annual gonorrhoea rates were analysed from 1981 to 1990 .
\end{abstract}

Setting-Outpatients of the department of genitourinary medicine.

Patients-A total of 850 females attending consecutively and having routine syphilis serology.

Main Results-The prevalence of antiH1V-1 in female attenders in 1989-1990 was $0.35 \%$ (3/850). Prevalence in the same clinic has remained statistically unchanged since the first female cases were identified in 1986. No cases of HIV-2, HTLV-1 or HTLV-2 were identified, and no early HIV-1 infection evidenced by the presence of p24 or RT antigenaemia was found. Female gonorrhoea rates continued to decline but other STD monthly/ annual rates have remained unchanged. Conclusions-Over the last 5 years prevalence of HIV-1 infection in females in our clinic has remained unchanged and other retroviral infections have remained absent. However, the unaltered rates of other genital infections, their potential role in the heterosexual spread of HIV-1 infection, and the lack of evidence for any major changes in female sexual behaviour suggests there is a need to remain vigilant. This work complements the MRC multicentre, unlinked, genitourinary medicine clinic, anonymous testing programme, and our group will continue to apply this simple methodology to specimens from female attenders to contribute to the surveillance of the evolving HIV-1 epidemic.

(Genitourin Med 1993;69:31-34)
Introduction

Worldwide, the commonest mode of transmission of HIV-1 and HIV-2 is by heterosexual intercourse, ${ }^{1}$ initially reported for SubSaharan Africa ${ }^{2}$ and more recently in South America, ${ }^{3}$ the USA ${ }^{4}$ the $\mathrm{UK}^{5}$ and South East Asia. ${ }^{6}$ Prostitution, frequency of partner change, ${ }^{7}$ genital mucus membrane damage, ${ }^{8}$ STD frequency, ${ }^{9}$ and altered host resistance $^{1011}$ have all been implicated as important factors associated with high rates of spread. Data from the USA, where the epidemic is 4 years further advanced than the UK, suggest a relentless rise in AIDS and HIV-1 infection in the heterosexual population; at present female AIDS cases associated with heterosexual exposure are $3 \cdot 42 \%(6460 / 188,348)$ of the total. ${ }^{12}$ Represented in this group of cases are those with risk factors associated with birth or sexual contact in a pattern II country, ${ }^{12}$ those with no risk factors, and those due to spread of infection by sexual partners belonging to primary risk groups. ${ }^{13}$ Certainly the present numbers indicate that the new cases of AIDS in heterosexuals will continue to rise well into the next century. ${ }^{14}$

Studies in the UK carried out amongst STD clinic patients, ${ }^{15-17}$ antenatal clinic attend$\operatorname{ers}^{1819}$ and babies ${ }^{20-22}$ have already revealed a small but consistent presence of HIV-1 infection in the heterosexual population. Many of these studies used anonymous testing, a method regarded as important where there is a low prevalence, to avoid compliance bias and ensure accurate surveillance data. ${ }^{2324}$

The aims of this anonymous study were firstly, to examine the trends in the prevalence of HIV-1, HIV-2, HTLV-1 and HTLV-2 in female STD clinic attenders and, secondly, to establish a baseline for further application of this simple methodology for future surveillance of the heterosexual HIV epidemic in this population.

\section{Methods}

During an 8 week period between November 1989 and January 1990 we studied 850 consecutive female patients attending the department of genitourinary medicine at The Middlesex Hospital, London and having routine serological tests for syphilis. Patients already attending the clinic as part of routine follow-up of HIV-1 infection were excluded. Age (in 5 year bands), nationality (in broad geographical zones: UK, rest of Europe, North America, Central/South America, Australasia, North Africa, Sub-Saharan Africa, India, Far

Mddesex School of

Medicine, Windeyer

Building, 46 Cleveland UK 
Table 1 Demographic features of females seen during 1987 and 1989-1990 study periods

\begin{tabular}{lcc}
\hline & 1987 & $1989-1990$ \\
\hline No of females seen & 412 & 850 \\
No (\%) not born in UK & $94(22 \cdot 8)$ & $210(24 \cdot 7)$ \\
No (\%) anti-HIV-1 positive & $4(0 \cdot 97)$ & $3(0 \cdot 35)$ \\
Mean age (range) years & $25(17-67)$ & $26 \cdot 8$ \\
& & $(15-70)^{\star}$ \\
No (\%) total anti-HBc positive & $40(9 \cdot 7)$ & $36(4 \cdot 0)$ \\
No (\%) UK anti-HBc positive & $19(4 \cdot 6)$ & $24(3 \cdot 7)$
\end{tabular}

No = number

*calculated from mid-point of 5 year age bands

[Similar data not collected in 1985 and 1986]

East, Mediterranean and others), diagnosis on the day of presentation and history of intravenous drug usage were taken from computer files and recorded on numbered record sheets. Anonymity was ensured by removing the patients clinic number from the record sheets and substituting a serum code number before results were analysed. This methodology was different from previous samples: in 1985 and 1986 no data were collected, and in 1987 when data were collected directly from notes. These changes were established to preserve anonymity but retain some basic information of value in future data analysis.

Serum samples were tested for anti-HIV-1 by a competitive enzyme-linked immunosorbent assay (ELISA: Wellcozyme HIV-1, Wellcome Diagnostics), for anti-HIV-2 by an immunometric HIV-1 +2 ELISA (Wellcozyme HIV-1+2, Wellcome Diagnostics), for antiHTLV-1 and 2 by gelatin particle agglutination (Serodia, Fujirebio, Inc) and for anti-HTLV-1 by an in-house competitive ELISA. All potential retrovirus antibody positive sera were confirmed by Western Blot analysis (Dupont Ltd). Only anti-HIV-1 positive sera from previous samples in 1986 and 1987 were available for testing for HTLV-1 and 2 .

HIV-1 p24 and reverse transcriptase (RT) antigens, markers of infection present prior to seroconversion, were measured using in-house ELISAs ${ }^{2526}$ by initially testing pools of 12 sera and further investigating those pools showing signal above test cut-off.

Hepatitis B core antibodies (anti-HBc) were measured by a modified passive haemagglutination assay (Green Cross Corporation) and confirmed by an in-house radioimmunoassay.

The annual gonorrhoea rate (number of females with gonorrhoea over the total number of female cases reported on the KC60 Depart- ment of Health quarterly returns) were analysed for women from 1981 to 1990 .

Ethical committee approval was obtained in 1985 and 1987 as part of ongoing anonymous point prevalence studies to examine the changing prevalence of retroviral infections in our clinic attenders. Data were analysed by MannWhitney $U$ test for differences in continuous variables and chi squared test for differences in proportions.

\section{Results}

In 1989-90 three of 850 women studied were anti-HIV-1 seropositive, an overall prevalence of $0.35 \%$ (table 1 ). This figure remains statistically unchanged since the first female cases were indentified in our clinic population $(0.5 \%$ in $1986 ; 0.97 \%$ in 1987 ; table 2 ). The three patients found in the present study were significantly older than the sample population (analysis was based upon the mid point figure for each positive case: $p=0.021$ ); all were anti$\mathrm{HBc}$ negative, and one had gonorrhoea at the time of testing. There was no significant difference in age, proportion of UK nationals and percentage of other nationalities in this sample and previous samples studied.

No patients in the 1989-1990 sample or previously identified anti-HIV-1 antibody positive females were seropositive for HIV-2, HTLV-1 or HTLV-2. Further, no markers of early HIV-1 infection (p24 and RT antigens) were detected in any samples.

The gonorrhoea rate (fig 1) had fallen from $3.84 \%(310 / 8054)$ in 1981 to $0.71 \%$ $(66 / 9189)$ by the end of $1989(p<0.01)$, a decline of $0.35 \%$ per year. It then rose to $0 \cdot 89 \%(79 / 8813)$ in 1990 (not significant).

The prevalence of anti-HBc in all females attending was $4.0 \%(36 / 850)$ and $3.7 \%$ $(24 / 640)$ in UK attenders. These figures were significantly lower than previous samples: 1987 total-9.7\%, UK-4.6\% (p<0.001); 1986 total-9.1\%, UK-4.7\% ( $<<0.001)$.

Of 850 females in the 1989-1990 sample $515(61 \cdot 0 \%)$ had a genital infection requiring inclusion in the annual clinic returns on the day of testing (table 3 ) and $240(28.0 \%)$ of the total sample had conditions likely to produce some loss of integrity or inflammation of the genital tract mucus membranes (table 3: numbers 2-7) compared with the 1987 sample when $271 / 412$ females $(65 \cdot 5 \%)$ had a genital infection and $106(25 \cdot 7 \%)$ fell into the latter

Table 2 Seroprevalence and demographic features for anti-HIV1 seropositive females between 1985-1990

\begin{tabular}{|c|c|c|c|c|c|c|}
\hline Year & Seroprevalence & $\begin{array}{l}\text { Age or } \\
\text { range (years) }\end{array}$ & Nationality & $\begin{array}{l}\text { Diagnosis } \\
\text { on the day }\end{array}$ & $A n t i-H B c$ & HIV risk \\
\hline 1985 & $0 / 133$ & - & - & - & - & - \\
\hline 1986 & $2 / 395$ & $\begin{array}{l}28 \\
23\end{array}$ & $\begin{array}{l}\text { UK } \\
\text { UK }\end{array}$ & $\begin{array}{l}\text { NK } \\
\text { NK }\end{array}$ & $\begin{array}{l}\text { NEG } \\
\text { POS }\end{array}$ & $\begin{array}{l}\text { NONE } \\
\text { IVDU }\end{array}$ \\
\hline \multirow[t]{3}{*}{1987} & $4 / 412$ & 23 & UK(SSA) & NSU contact & NEG & NONE \\
\hline & & & $\begin{array}{l}\text { UK(Europe) } \\
\text { UK }\end{array}$ & $\begin{array}{l}\text { HIV test } \\
\text { WARTS }\end{array}$ & NEG & NONE \\
\hline & & & UK & NAD & $\begin{array}{l}\text { NEG } \\
\text { POS }\end{array}$ & $\begin{array}{l}\text { NONE } \\
\text { IVDU^ }\end{array}$ \\
\hline $1989-1990$ & $3 / 850$ & $36-40$ & UK & NK & NEG & NONE \\
\hline & & $\begin{array}{l}31-35 \\
41-45\end{array}$ & $\begin{array}{l}\text { SSA } \\
\text { UK }\end{array}$ & $\begin{array}{l}\text { GC } \\
\text { NAD }\end{array}$ & NEG & NONE \\
\hline & & & Un & NAD & NEG & NONE \\
\hline
\end{tabular}

UK = United Kingdom resident; NK = not known; NEG = negative; POS = positive; GC = gonorrhoea; UK ()$=$ birth place IVDU $=$ intravenous drug user; $\mathrm{NAD}=$ no abnormality detected; SSA = Sub-Saharan Africa

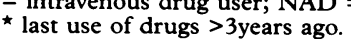


Figure Percentage (a) and numerical fractions (b) for rates of gonorrhoea for female (O) attenders at the Middlesex Hospital,

London during

1981-1990. Num. = numerator, Denom. = denominator.
A

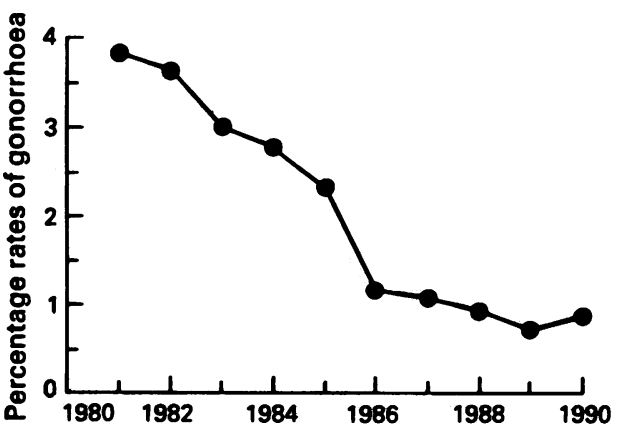

B

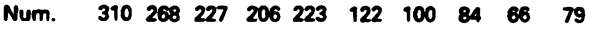
Denom. 80547351749273819605104319177903591958813

category (no significant differences).

Overall, there were no differences in the monthly rates of genital infections (monthly case number/total monthly cases) between the 1987 and 1989-1990 samples. During the course of the present study $84(9.9 \%)$ of females attenders requested an HIV-1 antibody test; similar figures were not available on earlier samples.

\section{Discussion}

The anti-HIV-1 seroprevalence $(0.35 \%)$ in this sample was statistically unchanged since 1986 when the first positive females were identified at our clinic. ${ }^{15}$ These positive cases were older than in previous years which may be relevant in terms of epidemic evolution. There was no evidence of HIV-2, HTLV-1 or HTLV-2 infection in the present or previous samples, and the absence of p24 and RT antigens excluded the possibility of pre-seroconversion cases in this study sample. This seroprevalence for heterosexual females in STD clinic attenders in London is in agreement with other recent studies. ${ }^{1727}$

Surrogate markers to detect possible changes in sexual behaviour revealed apparently contradictory results in this study. The gonorrhoea rates continued to fall significantly up to 1989 , and then rose in 1990, a change that was not significant but may reflect observations by

Table 3 A comparison of the proportions and monthly rates $\int$ of genital infections (GI) * during the study periods amongst 412 females in 1987 (1 month) and 850 females 1989-1990 (2 months)

\begin{tabular}{|c|c|c|}
\hline & $\begin{array}{l}1987 \\
\text { (number/\%) }\end{array}$ & $\begin{array}{l}1989-1990 \\
\text { (numbers } \% \text { ) }\end{array}$ \\
\hline $\begin{array}{l}\text { Total with GI diagnosis } \\
\text { Total with no GI diagnosis } \\
\text { 1. Total with vaginal candida } \\
\text { 2. Total with chlamydia } \\
\text { 3. Total with genital warts } \\
\text { 4. Total with genital herpest } \\
\text { 5. Total with trichomoniasis } \\
\text { 6. Total with gonorrhoea } \\
\text { 7. Total with syphilis } \\
\text { 8. Total unspecified } \\
\text { 9. Total requesting an HIV } \\
\text { test }\end{array}$ & $\begin{array}{c}271 / 65 \cdot 3 \% \\
141 / 34 \cdot 7 \% \\
37 / 9 \% \\
35 / 8 \cdot 5 \% \\
37 / 9 \% \\
22 / 5 \% \\
8 / 2 \% \\
1 / 0 \cdot 2 \% \\
3 / 0 \cdot 7 \% \\
128 / 31 \% \ddagger \\
\text { not recorded }\end{array}$ & $\begin{array}{c}515 / 61 \% \\
335 / 39 \% \\
155 / 18 \% \\
95 / 11 \% \\
66 / 8 \% \\
38 / 4 \cdot 5 \% \\
29 / 4 \% \\
10 / 1 \% \\
2 / 0 \cdot 2 \% \\
36 / 4 \% \\
84 / 10 \%\end{array}$ \\
\hline
\end{tabular}

others that show a reversal in the declining gonnorhoea rates seen in the last 5 years. ${ }^{28}$ The prevalence of anti-HBc was statistically lower in the 1989-1990 sample (4.0\%) compared with previous samples $(1987-9.7 \%$; $1986-9.1 \%$ ) but no changes were observed in the monthly rates of other STDs during the study periods. The fall in anti-HBc prevalence cannot entirely be accounted for by changes in the proportion of UK to non-UK females in the sample ${ }^{29}$ and we find it difficult to believe that such a fall within 2 years in a persistent marker of Hepatitis B virus infection was a reflection of changing sexual behaviour; this observation is being further investigated. The unchanged monthly, and annual rates (not presented here) of genital infections, especially those associated with some degree of damage to genital tract mucus membranes give cause for concern. The ulcerating STD associated with Haemophylus ducreii has been suggested as a co-factor in HIV-1 transmission in Africa and the USA, ${ }^{3031}$ and other pathogens like herpes simplex virus ${ }^{32}$ and Treponema pallidum ${ }^{33}$ have been similarly implicated. Further, in a prospective study in African prostitutes ${ }^{9}$ seroconversion for anti-HIV-1 in individuals with low incidence of ulcerating STDs was significantly associated with non-ulcerating STD pathogens (Chlamydia trachomatis, Neisseria gonnorhoeae, Trichomonas vaginalis) during the period preceding seroconversion, and the authors suggest a causal association. The mechanism in both these situations is, at least in part, presumed to be disruption in the integrity of normal skin or mucosa. The role of all these pathogens in HIV-1 transmission is made more important by the recent work of Haseltine et $a l^{3435}$ demonstrating that tissue dendritic cells which are phagocytic, CD4 positive, antigen-processing cells of the reticuloendothelial system in the genitourinary (GU) and gastrointestinal (Gl) tracts become infected with HIV-1 and produce 50 times as much virus as infected CD4 positive lymphocytes. They proposed that these cells may be infected locally in GU and GI tracts by HIV-1 and then present intact virions to other cells of the immune system (that is, helper lymphocytes and macrophages) at sites distant from the site of infection. ${ }^{34}$ Thus, any pathogen inducing a local inflammatory reaction in these sites, where tissue dendritic cells are part of the inflammatory infiltrate may serve as a co-factor for co-existing HIV-1 to infect the host. This evidence, together with data from elsewhere that heterosexual populations continue to engage in high risk sexual activities ${ }^{36}{ }^{37}$ and show a significant but relatively poor increase in condom usage ${ }^{3839}$ have led us to conclude that those carrying out population serosurveillance must remain vigilant.

The implication of an evolving heterosexual epidemic with a viral agent that is transmitted by sexual intercourse, ${ }^{1}$ has a significant rate of vertical transmission, ${ }^{40}$ is presently incurable, and ultimately fatal, is that it is not only a threat to individuals but eventually whole populations. Our group has been one of the pioneers in developing laboratory methods and 
strategies for serosurveillance of HIV-1 infection in the UK since $1982 ;^{15} 1620-222541-44$ much of this work has now devolved to others, for example the MRC multicentre, unlinked, genitourinary medicine clinic, anonymous testing programme. ${ }^{245}$ Using our present methodology, which is complementary to such studies by providing additional local data on the prevalence of human retroviral infections in our sexually active female population, we will continue to contribute to the overall serosurveillance of the evolving epidemic.

The authors thank all staff in the Division of Virology and Department of Genitourinary Medicine, past and present, who have contributed, and without whom this work would not be possible.

1 Piot P, Laga M, Ryder R. The global epidemiology of HIV1 infection: continuity, heterogeneity and change. $\mathcal{F}$ Acquir Immune Defic Syndr 1990;3:403-12.

2 Sato PA, Chin J, Mann JM. Review of AIDS and HIV infection: global epidemiology and statistics. AIDS 1989;3:3301-7.

3 Quinn TC, Narain JP, Zacarian FRK. AIDS in the Americas: a public health priority for the region. AIDS 1990;4:709-24.

4 Holmes KK, Karon JM, Kreiss JK. The increasing frequency of heterosexually acquired AIDS in the United quency of heterosexually acquired AIDS in the United

5 Communicable Disease Surveillance Centre. Increasing AIDS and HIV-1 in UK women. Communicable Disease Report. 1990, week 47 .

6 Cameron DW, Padrian NS. Sexual transmission of HIV and the epidemiology of other sexually transmitted diseases. AIDS 1990;4:S99-S103.

7 Piot P, Plummer FA, Mhalu FS, Lamboray J-L, Chin J, Mann JM. AIDS: an international perspective. Science 1988;239:573-9.

8 Johnson AM, Laga M. Heterosexual transmission of HIV. AIDS 1988;2:49-56.

9 Nzila N, Laga M, Thiam MA, et al. HIV and other sexually transmitted diseases among female prostitutes in Kinshasa. AIDS 1991;5:715-21.

10 Quinn TC, Piot P, McCormick JM, et al. Serological and immunological studies in patients with AIDS in North America and Africa. $¥ A M A$ 1987;257:2617-21.

11 Forrest BD. Women, HIV and muosal immunity Lancet 1991;337:835-6.

12 Statistics from Centre for Disease Control. AIDS 1991, 5:1399-402.

13 Stoneburner RL, Chiasson MA, Weisfuse IB, Thomas P The epidemic of AIDS and HIV-1 infection amongs heterosexuals in New York City. AIDS 1990;4:99-106.

14 Mann JM. The understated HIV-1 epidemic-press release. $B B C T V$ News 1992.30 May.

15 Carne CA, Weller IVD, Loveday C, et al. Prevalence of antibodies to human imunodeficiency virus, gonorrhoea rates, and changing sexual behaviour in homosexual men in London. Lancet 1987; i:656-8.

16 Loveday C, Pomeroy L, Weller IVD, et al. Human immunodeficiency viruses in patients attending a sexually trans-
mitted disease clinic in London 1982-87. BM7 1989; 298:419-23.

17 Anonymous. Collaborative study by consultants in genitourinary medicine and Public Health Laboratory Service. HIV infection in patients attending clinics for sexually transmitted disease in England and Wales. BMF 1989; 298:415-8.

18 Heath RB, Grint PCA, Haridman AE. Anonymous testing of women attending antenatal clinics for evidence of infection with HIV. Lancet 1989;i:1394-7.

19 Banatvala JE, Chrytie IL, Palmer SJ, Kenney A. Retrospective study of HIV, hepatitis $B$, and HTLV-1 infection at a London antenatal clinic Lancet 1990;335:859-60.

20 Peckham CS, Tedder RS, Brigos M et al. Prevalence of maternal HIV infection based on unlinked anonymous testing of newborn babies. Lancet 1990;335:516-9.

21 Ades AE,Parker S, Berry T, et al. Prevalence of maternal
HIV-1 infection in Thames region: results from anonymous unlinked neonatal testing. Lancet 1991:337: 1562-5.

22 Tappin DM, Girdwood RWA, Follett EAC, Kennedy R Brown AJ, Cockburn F. Prevalence of maternal HIV infection in Scotland based on unlinked anonymous testing of newborn babies. Lancet 1991;337:1565-7.

23 Anonymous. Testing for HIV infection. Lancet 1988 i: 1293

24 Gill ON, Adler M, Day NA. Monitoring the prevalence of HIV: foundation for a programme of unlinked anonymous HIV testing. BMF 1989;299:1295-8.

25 Smith AM, Williams H, Tedder RS, et al. The relationship between serial changes in HIV p24 protein, antibodies to HIV structural proteins and disease progression. IVth International Conference on AIDS (Stockholm) 1988, Abst. 1622

26 Loveday C, Williams H, Tedder RS. An ELISA assay for the measurement of HIV-1 RT antigen. VIth International Conference on AIDS (San Francisco) 1990, Abst. FA329.

27 Public Health Laboratory Service Working Group. Prevalence of HIV antibody in low risk groups in England. $B M \mathcal{F}$ 1989;298:422-3.

28 Singaratrom AE, Boag F, Barton SE, Hawkins DA, Lawrence AG. Preventing the spread of HIV infection. BMF 1991;302:249.

29 Gilson RJC, De Ruiter A, Waite J, Loveday C, Kelly G Weller IVD. Seroprevalence of hepatitis $B$ virus infection in patients attending a genitourinary medicine clinic. In Hepatitis B: a sexually transmitted disease in heterosexuals. Piot $P$ and Andre FE eds 1990, Elsevier Science Publishers B.V. (Biomedical Division)

30 Simonsen IN, Cameron DW, Gakinya MN. et al. Human HIV infection amongst men with sexually transmitted diseases: Experience from a centre in Africa. $N E n g f M e d$ diseases: Experienci

31 Cameron DW, Simonsen JN, D'Costa W, et al. Female to male transmission of human immunodeficiency virus, type 1: risk factors for seroconversion in men. Lance ;ii:403-7.

32 Holmberg SD, Stewart JA, Gerber AR et al. Prior herpes simplex virus, type 2 , infection as a risk factor for HIV infection. $\mathscr{F A M A} 1988 ; 259: 1048-50$.

33 Quinn TC, Glasser D, Cannon RD. HIV infection amongst patients attending clinics for sexually transmitted diseases. N Eng Med 1988;318:197-203.

34 Haseltine WA. Virology of AIDS: Molecular Aspects (keynote speech) VIIth International Conference on AIDS (Florence) 1991. Th.1.

35 Langhoff E, Terwilliger EF, Poznansky MC, Kallander $\mathrm{KH}$ Haseltine WA. Prolific HIV-1 growth in human dendritic cells. VIIth International Conference on AIDS (Florence) cells. VIIth Internation

36 DeBuono BA, Zinner SH, Daamen M, McCormack WM. Sexual behaviour of college women in 1985,1986 and 1989. N Eng f Med 1990;322:821-5.

37 Breakwell GM, Fife-Schaw C. Sexual activities and preferences in United Kingdom sample of 16 to 20 -year-olds. Arch Sex Behav 1992;21:271-93.

38 Evans BA, McCormick SM, Bond RA, MacRae KD, Thorpe RW. Human immunodeficiency virus infection, hepatitis B infection, and sexual behaviour of women attending a genitourinary medicine clinic. $B M \mathcal{F}$ 1988;296:473 -5.

39 Sittitrai W, Brown T, Sterns J. Opportunities for overcoming the continuing restraints to behaviour change and HIV the continuing restraints to behaviour
risk reduction. AIDS 1990;4:269-76.

40 European Collaborative Study. Children born to women with HIV-1 infection: natural history and risk of transmiswith HIV-1 infection: natural histo
sion. Lancet 1991;337:253-60.

41 Carne CA, Weller IVD, Sutherland S et al. Rising prevalence of human T-lymphotrophic virus, type 3 (HTLV III) infection in homosexual men in London. Lancet 1985; i:1261-2.

42 Cheingsong-Popov R, Weiss RA, Dalgleish A, et al. Prevalence of antibodies to human t-lymphotropic virus type III in AIDS and AIDS-risk patients in Britain. Lance 1984;ii:477-80.

43 Lambert MA, Price G, Coleman J. Risk of blood borne infection to accident and emergency health care workers. Abst.: Arch Emerg Med 1992;9:87.

44 Cummins AJ, Tedder RS. Inadequate information on neddlestick accidents. Lancet 1992;339:1178-9.

45 Heptonstall J, Gill ON. The legal and ethical basis for unlinked anonymous HIV testing. Commun Dis Rep 1989; 48:3-6. 